\title{
A PONDERAÇÃO PREVIDENCIÁRIA E AS CARACTERÍSTICAS ESPECÍFICAS DO SEGURADO ESPECIAL NODERSTINO
}

\author{
Juraci Mourão Lopes Filho' \\ Daniela Montezuma da Silva ${ }^{2}$
}

\section{RESUMO}

O presente artigo, através de um estudo bibliográfico, realça e questiona as desigualdades do critério etário da Lei $\mathrm{n}^{\circ} 8213 / 91$, que atualmente rege a aposentadoria por idade aos segurados especiais no Brasil. $\mathrm{O}$ assunto tem relevância no contexto da igualdade material, centrada na expectativa de vida do trabalhador rural, na idade do início do labor, nas condições geoclimáticas, nas doenças degenerativas próprias de cada região e nas diferenças de tratamento com relação ao trabalhador urbano. Na realidade, com o intuito de evitar injustiça, o legislador deveria ter realizado uma ponderação de princípios mais atenta a esses fatores de relevo.

Palavras-chave: Sopesamento; Ponderação; Robert Alexy; Segurado Especial; Legislador.

\section{THE PREVENTIVE WEIGHT AND THE SPECIFIC CHARACTERISTICS OF THE NORTHEAST SPECIAL INSURANCE}

\begin{abstract}
This article, through a bibliographic study, highlights and questions inequalities in the age criterion of Law No. 8213/91, which currently governs the retirement age of special insured persons in Brazil. The subject is relevant in the context of material equality, centered on the life expectancy of the rural worker, the age of the beginning of the labor, the geoclimatic conditions, the degenerative diseases typical of each region and the differences in treatment with the urban worker. In fact, in order to avoid injustice, the legislator should have carried out a weighting of principles more attentive to these important factors.
\end{abstract}

Keywords: Weighting; Poderation; Robert Alexy; Special Insured; Legislator.

\footnotetext{
${ }^{1}$ Doutor (UNIFOR) e Mestre (UFC) em Direito Constitucional. Pós-graduado lato sensu em Direito Processual Civil (UFC). Professor de Direito da Unichristus. Procurador do Município de Fortaleza. Advogado. E-mail: $<$ juracimourao@gmail.com>.

${ }^{2}$ Advogada. Mestranda em Direito pela Unichristus. Especialista em Direito Previdenciário. Bacharel em enfermagem. Ex conciliadora da Justiça Federal no Estado do Ceará. Professora do Instituto Intellegens. E-mail: <Danielamontezuma@hotmail.com>.
} 


\section{INTRODUÇÃO}

A agricultura é umas das principais bases da economia do Brasil. Evidencia-se uma atividade do setor primário em que a terra é cultivada e colhida para subsistência, industrialização ou comércio nacional e internacional. Os atores envolvidos nesta atividade (objeto do presente estudo), os segurados especiais, participam diretamente desse processo, mas não detêm, via de regra, maiores riquezas e sofrem arduamente até conseguirem conquistar direitos assegurados pela Constituição Federal de 1988, em especial a aposentadoria por idade rural.

A vida do segurado especial nordestino, mais especificamente, apresenta-se árdua, mesmo frente aos avanços tecnológicos. A exposição ao sol caracteriza-se como um fator nocivo à saúde e à integridade física. São inúmeros os rurícolas que, antes da faixa etária legal para realizar o requerimento de uma aposentadoria por idade, tornam-se parcial ou permanentemente incapacitados, quer por exposições ao sol e agrotóxicos, ou acometidos de comorbidades específicas tais como doenças na coluna, nas articulações ou, ainda, são acometidos por acidentes de trabalho. Sendo assim, é importante também saber em qual lugar o agricultor desenvolve suas atividades, para que assim possa ter um tratamento diferenciado no momento da solicitação de benefícios previdenciários, pautado numa análise no caso concreto, visando compreender as limitações e barreiras de forma ponderada frente a suas comorbidades e local do labor. Jessica Pronestino de Lima Moreira nos diz que:

Ações de promoção, proteção, tratamento e recuperação da saúde devem ser
analisadas segundo o contexto social de onde são demandas, pois trabalhadores
e moradores da zona rural possuem características distintas na sua forma de
viver, trabalhar e se relacionar com o ambiente. Neste sentido, selecionar este
ambiente para verificar se existem diferenças entre as ocupações dos
trabalhadores faz-se necessário (MOREIRA, 2015, online).

Uma pesquisa importante que irá proporcionar parâmetros objetivos no momento da ponderação dos princípios que regem a Lei no 8213/91 seria a visualização entre a população com ocupação agrícola, que atinge $15,5 \%$ de pessoas idosas, contra apenas $5 \%$ na população com ocupação não agrícola e estes estão mais concentrados na Região Nordeste do Brasil $(47,7 \%)$, seguida pela Região Sudeste $(21,7 \%)$. Diante desse percentual já se evidencia uma diferença alarmante que deve ser direcionada para um tratamento diferenciado no tocante a uma futura proteção previdenciária. A contrário senso, observa-se entre os trabalhadores com ocupação não agrícola (47,4\%, na Região Sudeste e 22,2\%, na Região Nordeste). Ademais, evidencia-se uma maior proporção dos trabalhadores com ocupação agrícola que não possuem 
rendimento ou recebem até um salário mínimo $(75,2 \%)$, enquanto entre os não agrícolas a proporção é de $53,0 \%$.

Segundo Pronestino (MOREIRA, 2015, online), existe um maior índice de morbidade referida entre os trabalhadores da atividade agrícola no Brasil, de acordo com a ocupação exercida. Diante da pesquisa Nacional por Amostra de Domicílios vemos que as três morbidades de maior incidência nos agricultores são as doença da coluna com $21,1 \%$, a hipertensão arterial com17,3\% e a artrite ou reumatismo finalizando com 7,7\%. Outras doenças acometem os trabalhadores rurais tais como as doenças no coração, a depressão, o câncer e a diabetes.

Nesse âmbito, também foi verificado que quanto mais anos de estudo e acesso ao Sistema Único de Saúde, mais também é aumentada a chance do agricultor aferir sua saúde como boa. Em comparação com a Região Norte, residir nas regiões Sul, Sudeste ou Centrooeste do país aumenta a chance de referir saúde como boa, já que nessas regiões temos um maior índice de desenvolvimento. Evidencia-se que, quanto maior a renda do trabalhador, maior a chance de referir saúde como boa. Ter alguma doença diminui a chance de referir saúde boa, e essa chance é cada vez menor conforme aumenta a gravidade da doença.

Segundo o INCA (2017, online), as mulheres da região nordeste são mais acometidas por câncer de pele que os homens, já que o maior índice de câncer de melanoma é encontrado na região sul, tendo como fator agravante a cor da pele branca dos agricultores da região.

Existem ainda inúmeros condicionantes externos desfavoráveis à vida e à dignidade do trabalhador rural, tais como a seca do nordeste, o aspecto degenerativo de suas patologias e sua expectativa de vida reduzida.

Devido a essa exposição ao sol e outros fatores que afetam diretamente a integridade física dos segurados especiais, o legislador entendeu conceder uma redução de cinco anos na idade para a concessão de aposentadoria por idade de todos os trabalhadores rurais no Brasil, sem distinção das contingências regionais. Os homens têm direito a aposentadoria por idade rural aos 60 anos, e as mulheres, por questão de igualdade material, aos 55 anos, já que o segurado urbano adquire seu direito a uma aposentadoria por idade aos 65 e 60 anos para homens e mulheres respectivamente.

Desse modo, restou clara a tentativa do legislador em ter idealizado um projeto de lei, que tentaria buscar uma justiça pautada no sofrimento árduo desses trabalhadores, pela redução etária. Contudo, não restou evidenciada uma ponderação em abstrato na lei sancionada. A lei $n^{\circ} 8213 / 91$, no quesito idade, não distinguiu o trabalhador rural diante das inúmeras dificuldades 
e diferenças regionais que estão inseridas na vida dos segurados especiais do Brasil. A lei deveria ter contemplado todos os seus objetivos no território nacional trazendo, assim, uma ponderação em abstrato mais atenta a inúmeros fatores que influenciam na incidência dos princípios constitucionais para que a idade não fosse unificada e pautada em critério único e geral em todo o país.

Diante de uma hermenêutica constitucional e da dogmática dos direitos fundamentais, busca-se, por meio deste estudo, uma revelação de parâmetros mais dignos na aposentadoria por idade rural dos segurados especiais, no contexto da faixa etária nas diversas regiões do Brasil, traçando ainda um paralelo com o paradigma dos agricultores da região Sul e Nordeste.

Identifica-se, então, uma diferenciação de condições fáticas na incidência dos princípios constitucionais como, por exemplo, a expectativa de vida do segurado rural nas diversas regiões do país. Diante disso, torna-se primordial a realização do estudo dos valores dos princípios constitucionais e previdenciários, que o legislador quis evidenciar na Lei $\mathrm{n}^{\circ}$ $8.213 / 91$.

Questiona-se, ainda, quais seriam os princípios em concorrência quando da análise do sopesamento dos princípios constitucionais e previdenciários realizado pelo legislador. Diante disso, o presente estudo será direcionado a demonstrar algumas falhas do legislador, quando de forma abstrata não realizou uma ponderação dos princípios envolvidos na discussão, como indica a teoria de ponderação entre princípios envolvidos trazida por Robert Alexy. A referida lei, a priori, considerou como homogêneo o critério da idade, e o desafio será analisar como o legislador poderia ter feito uma ponderação em abstrato considerando as diversidades das regiões brasileiras, para que o direito a uma aposentadoria por idade rural tornasse mais isonômico em todo território nacional.

A ideia de idade igualitária em todo território nacional falseia o entendimento adequado, trazendo uma proteção diante da contingência idade avançada com uma inadequada sensação pautada na igualdade, que, no entanto, é apenas formal. Portanto, seria justo fixar a idade de 60 anos (homem) ou 55 anos (mulher) para que todos os agricultores do país tivessem direito a uma aposentadoria por idade digna? Será proposto que não.

Nem todo brasileiro está inserido nos mesmos parâmetros, pois estariam trabalhando em regiões diferentes e em condições diversas de labor. Desse modo, seria possível, no caso em abstrato, haver essa relativização em sintonia com os critérios das diversas regiões e suas implicações? Na verdade, no tocante à taxa de mortalidade dos segurados especiais, esta se torna diferenciada a depender das diferentes regiões do Brasil. Seria possível, portanto, que 
quando os agricultores, segurados especiais, completassem 15 anos de atividade rural e 60 anos se homem ou 55 anos se mulher, já estariam próximo ao seu falecimento ou a gozar um diminuto tempo de benefício. Toda essa problemática será analisada segundo a teoria da ponderação de Robert Alexy, diante do sopesamento dos princípios da isonomia, da proteção à velhice e à saúde, da universalidade de cobertura e o princípio da seletividade, da distributividade na prestação dos benefícios e serviços.

Mediante esta pesquisa bibliográfica será possível evidenciar uma crítica à legislação atual, que tornou o critério etário unificado para todas as regiões do Brasil, quando existem diversidades de acordo com a localidade em que o segurado especial labora. Do mesmo modo, sinalizar-se-á para os meios judiciais disponíveis para correção dessa ponderação em abstrato realizada de maneira inadequada ou parcialmente suficiente.

\section{COMO VIVE O SEGURADO ESPECIAL NO BRASIL}

Desde o ano de 1971 que o Brasil começou a olhar de uma forma mais protetiva para o trabalhador rural. Foi mediante o Prorural, ligado ao Funrural, que se instituiu essa proteção. Nessa época, foi instituído pela Lei Complementar $n^{\circ} 11$ a concessão de aposentadorias por idade e invalidez para trabalhadores maiores de 70 anos de idade, no valor de meio salário mínimo aos trabalhadores rurais. As mulheres se tornariam beneficiadas diretamente caso fossem chefes de família ou assalariadas rurais, mas essa era uma difícil hipótese à época. Desse modo, a maioria das mulheres agricultoras não podiam se aposentar nessa época. Neste contexto, o programa estava sendo garantido, uma vez que a lei que o criou também efetivou a forma de obtenção de recursos para a sua implementação. Inúmeros doutrinadores ressaltaram a importância desse mecanismo para o que seria a maior conquista social do setor.

Contudo, apesar do grande avanço advindo da instituição do Prorural, foi somente após a Constituição Federal de 1988 que a proteção social no Brasil tomou forma mais robusta, por meio da Seguridade Social: Saúde, Assistência e Previdência Social.

Sendo assim, somente após a lei no 8.213/91 (Planos de Benefícios), houve a previsão legal do acesso universal de idosos e inválidos do meio rural, de ambos os sexos, à previdência social, em regime especial, com direito a benefícios no valor de um salário mínimo, desde que comprovassem o exercício da atividade rural na condição de produtor, parceiro, meeiro, arrendatários rurais, garimpeiro e pescador artesanal, bem como seus cônjuges que exercessem atividades em regime de economia familiar, sem empregados permanentes. Como bem observa 
Berwanger (2007, p. 98), a Constituição garantiu plena inserção protetiva ao trabalhador rural em regime de economia familiar deferindo, inclusive, a forma de contribuição, diferenciada com relação aos demais segurados.

O segurado especial, portanto, é aquele pequeno agricultor que tem a terra como fonte única de subsistência, retirando dela o seu alimento e, como meio de produção, negociando o produto excedente junto aos pequenos comerciantes urbanos. A venda desse produto excedente serve para que o agricultor possa adquirir outros alimentos, tais como o açúcar e o sal. Importante ressaltar que cerca de $36 \%$ da população brasileira vivem como segurados especiais no meio rural, segundo levantamento do Ministério do Desenvolvimento Agrário em 2015 (LEAL, 2015, online).

Nos termos do art. 48 da lei n. ${ }^{\circ} 8.213 / 91$, a aposentadoria por idade será devida ao segurado que, cumprida a carência exigida na lei, completar 65 anos de idade, se homem, e 60, se mulher. No entanto, o $\S 1^{\circ}$ do mesmo artigo assevera que esses limites são reduzidos para 60 e 55 anos no caso de trabalhadores rurais, respectivamente, homens e mulheres. Sendo assim, a aposentadoria por idade, do trabalhador rural, segurado especial, deve comprovar o exercício de atividade rural, ainda que de forma descontínua, no período imediatamente anterior ao requerimento do benefício, por tempo igual ao número de meses de contribuição correspondente à carência do benefício pretendido. Assim, o trabalhador rural não precisaria comprovar a carência da tabela do artigo 142, não lhe sendo exigida a comprovação de vínculo empregatício. A previsão legal encontra-se no artigo 143 da lei n. ${ }^{\circ}$ 8.213/91.

Berwanger (2007, p. 124) diz que milhares de segurados especiais ajuizaram ações previdenciárias buscando o reconhecimento do direito à aposentadoria por tempo de contribuição, comprovando o efetivo recolhimento na forma do artigo 25 (recolhimento sobre a produção comercializada). No entanto, o Superior Tribunal de Justiça concluiu que somente caberia a concessão desse benefício se o segurado tivesse contribuído facultativamente. A palavra final como resposta foi dada sobre esta questão, o Superior Tribunal de Justiça editou a Súmula $n^{\circ} 272$ : “O trabalhador rural, na condição de segurado especial, sujeito à contribuição obrigatória sobre a produção rural comercializada, somente faz jus à aposentadoria por tempo de serviço, se recolher contribuições facultativas".

Esse é um aspecto que merece ser avaliado e ponderado, principalmente porque o segurado especial, o agricultor, labora por inúmeros anos, e somente pelo critério idade pode requerer a sua aposentadoria sem a necessidade de realizar contribuições como facultativo. Aprioristicamente, diante dos agentes nocivos à sua saúde e integridade física, eles mereceriam 
uma aposentadoria por tempo de contribuição, ou melhor, por tempo de labor rural. Nesse aspecto, o legislador deveria ter sopesado os critérios desfavoráveis, com uma concessão de benefício a tempo de ser desfrutado plenamente ainda por alguns anos pelos rurícolas.

Importante ressaltar, os aspectos que tornam os agricultores brasileiros diferentes de acordo com as diversas regiões, matéria central do presente artigo, que busca uma justiça pautada na ponderação dos princípios que regem o direito a uma aposentadoria justa para os trabalhadores rurais, mais especificamente traçando diferenças entre os que moram no Sul e no Nordeste. A maioria dos agricultores no Brasil são casados e com idade entre 35 e 55 anos. Entretanto, o primeiro critério a ser avaliado neste estudo é o da escolaridade. Na Região Sul, $50 \%$ dos agricultores possuem o ensino fundamental incompleto; $22,7 \%$ possuem o ensino fundamental completo; $9,1 \%$ os que possuem ensino médio incompleto e 18,2\% os que têm o ensino médio completo (MENEGAT, 2010, online).

Deve-se destacar ainda uma informação relevante já amplamente divulgada pela imprensa, que a escolaridade nas áreas rurais é expressivamente inferior a das áreas urbanas. $\mathrm{O}$ percentual de pessoas com 18 anos ou mais de idade sem escolaridade era de $8 \%$ nas áreas urbanas em 2010, e nas áreas rurais já era de 25\%. Enquanto isso, mais de 18\% dos residentes urbanos possuía nível superior (completo ou incompleto), entretanto nas áreas rurais a participação deste grupo era quase que insignificante (apenas 3\%). (MAIA; BUAINAIN, 2015, online).

Em um aspecto mais amplo, cerca de 26,6\% dos trabalhadores rurais do nordeste são analfabetos, enquanto no sudeste encontra-se somente 7,8\%. A diferença é grande a ponto de causar um impacto bem representativo na economia das diversas regiões.

O Brasil, portanto, por ser um país que apresenta inúmeras desigualdades em suas diversas localidades, passa por uma disparidade socio-econômica de Norte a Sul, de Leste a Oeste, bem mais acentuada e se assemelhando a países da África e da América Latina. Vive-se em um país em que cabem diversos países. As diferenças regionais são o exemplo dessa problemática. Mas a escolaridade não é o único critério que deve ser ponderado diante do aspecto objetivo etário unificado da lei $\mathrm{n}^{\circ} 8213 / 91$, que proporciona a aposentadoria por idade ao trabalhador rural aos 55 anos ou 60 anos no Brasil. Temos ainda a situação climática do trabalhador rural, bem como relevo, solo e vegetação da região onde exerce seu labor.

Outro aspecto que merece ser ressaltado é a faixa etária com que o trabalhador rural inicia seu trabalho no campo. Normalmente, um filho com oito anos já começa a ajudar os pais, só conseguindo sua aposentadoria aos 55 ou 60 anos, ou seja, existindo a obrigação de laborar 
por mais de 43 anos. Em sentido oposto, de forma não isonômica, verifica-se que aposentadoria por idade urbana é concedida com apenas 15 anos de labor, uma vez que o trabalho urbano não é iniciado tão cedo. É certo que uma das primeiras medidas a serem implementadas, a par da proposta aqui apresentada, seria o combate ao trabalho infantil no campo, mas, ainda assim, não elidiria por completo o maior tempo de esforço, porque, efetivamente, o trabalhador rural inicia suas atividades em idade mais tenra se comparado com o urbano.

Portanto, a aparente ideia de fixação de uma idade mínima uniforme de 65 anos para
o acesso à aposentadoria é um verdadeiro atentado aos direitos dos trabalhadores(as)
rurais, contingente que começa a trabalhar muito cedo no campo e sob condições de
vulnerabilidade física.
Com efeito, para um trabalhador rural e uma trabalhadora rural que começaram a
trabalhar, em média, aos 12 anos, a tendência é a de terem que trabalhar,
respectivamente, 48 e 43 anos contínuos para ter acesso à aposentadoria
(GONÇALVES, 2016, p. 14).

Os critérios sobre a expectativa de vida e a idade média de aposentadoria do homem do campo são fatores que não podem passar despercebidos quando se busca uma justiça pautada numa ponderação principiológica a respeito do critério objetivo etário da lei no 8213/91. Galiza e Valadares (2016, p. 124) justificam muito bem esses pontos ao ressaltarem que "se a penosidade e o início precoce da atividade rural já são argumentos suficientes para justificar a diferença de 5 anos na idade mínima para requerer a aposentadoria por idade, há ainda outras importantes considerações a fazer”. E nessas importantes considerações é que pautamos todos os argumentos que provocam no caso concreto uma injustiça no tocante à aposentadoria dos segurados especiais no Brasil.

Um argumento seria a expectativa de vida média dos trabalhadores rurais, que atinge parâmetros de 67 anos, portanto o tempo que irão usufruir de suas aposentadorias é insignificante em relação ao tempo de labor rural exercido. Ademais, existem algumas localidades que, de acordo com o IBGE, a expectativa de vida é de aproximadamente 65 anos. Neste parâmetro, podemos analisar a diferença entre a expectativa de vida do agricultor e do homem brasileiro em geral, que é de 75,7 anos. Portanto, temos uma diferença de 10,7 anos que deveria ter sido mais bem avaliada pelo legislador no momento da criação da lei. E esses referenciais restam evidentes na região nordeste com mais representatividade.

Entre as 19 cidades com esperança de vida de aproximadamente 65 anos, cinco se localizam na Paraíba, três em Alagoas, sete em Pernambuco e quatro no Maranhão, todas no Nordeste do país. Na outra ponta da tabela, com expectativa de vida ao redor de 78 anos, estão 20 municípios de Santa Catarina (CRUZ; BRANCO, 2016, online).

Outra informação é que, apesar dos avanços da medicina, a taxa de mortalidade e a sobrevida dos agricultores não melhoraram com o passar dos anos. As descobertas da medicina nos últimos 10 anos foram pautadas em pesquisas a respeito de doenças infecto contagiosas 
como a AIDS e outras endemias. Os agricultores em sua maioria são acometidos por doenças degenerativas que vão se agravando com o passar dos anos, favorecendo, assim, uma alta taxa de mortalidade em relação aos trabalhadores urbanos, bem como o recebimento de benefícios por incapacidade. Essas doenças são a diabetes, as doenças na coluna e o câncer de pele.

Sendo assim, diante dos critérios apresentados, quais sejam, a mortalidade, doenças degenerativas, baixa taxa de escolaridade, início de vida laboral precoce e clima, iniciar-se-á a discussão sobre a Teoria dos Direitos Fundamentais, com especial atenção às considerações de Robert Alexy, que irá proporcionar uma visão mais ampla sobre os princípios que regem a aposentadoria por idade dos trabalhadores rurais buscando, em um segundo momento, a avaliação crítica da desconsideração da ponderação em abstrato feita pelo legislador ao tratar de forma igualitária a idade em todas as Regiões do Brasil.

O pensar de forma diferenciada através de uma prática de políticas públicas de acordo com as diferentes regiões, não chega a ser algo inédito. Ao defender políticas públicas que respeitem a diversidade entre as regiões, o pesquisador Fernando Albuquerque fala que seria um processo complexo e difícil adaptar uma reforma da Previdência às diferenças culturais, sociais e econômicas das diversas localidades do Brasil (CRUZ; BRANCO, 2016, online). Entretanto, já temos pesquisadores idealizando esses entendimentos. Uma aposentadoria ao trabalhador rural que tivesse critérios etários de acordo com as contingências regionais não nos parece algo inatingível. Nos dias atuais o Supremo Tribunal Federal, já entendeu pela inconstitucionalidade de critérios objetivos do Benefício Assistencial ao Portador de deficiência, para que sejam analisados os parâmetros de hipossuficiência no caso concreto, afastando do critério de renda de $1 / 4$ do salário mínimo instituído pela Lei 8742/93. Portanto não seria impossível no momento da concessão de um benefício de aposentadoria por idade rural, serem afastados os critérios objetivos etários, tendo assim uma análise no caso concreto de acordo com as contingências regionais no momento da concessão do benefício pleiteado. As informações no momento da pesquisa a ser feita pela autarquia previdenciária, poderia ser pautada na averiguação do local onde o labor foi exercido com suas especificidades, idade de início do labor rural, nível de escolaridade e morbidades presentes. Podendo o critério etário ser relativizado a menor dependendo do caso concreto.

\section{OS PRINCÍPIOS DO DIREITO PREVIDENCIÁRIO E CONSTITUCIONAIS QUE REGEM A LEI Nº 8213/91}


Os princípios constitucionais e previdenciários são de suma importância para a ciência do direito, e constituem o alicerce do ordenamento jurídico brasileiro, protegendo e dando sustentabilidade aos direitos que surgem destes princípios, alicerçando a efetividade da justiça e proporcionando a integralização da ciência.

Mais especificamente, quando se fala em aposentadoria por idade, logo se pensa em alguns princípios que regem esse benefício: o princípio da isonomia, o princípio da universalidade de cobertura, o princípio da seletividade e distributividade na prestação dos benefícios e serviços, o princípio das desigualdades sociais e, por fim, o princípio da equivalência urbano-rural.

O princípio da isonomia é aquele que releva especial relação com a democracia, pois indica um tratamento de justiça para os cidadãos. Encontra uma importância relevante dentro dos princípios constitucionais, mas de grande complexidade. Para sua completa análise tornase necessário entender o contexto cultural e histórico em que foi criado. Esse princípio tem feito parte das antigas civilizações, contudo já foi muitas vezes desrespeitado por entrar em atrito com os interesses das classes dominantes. Segundo a Constituição Federal, o princípio da igualdade está previsto no artigo $5^{\circ}$ e que proclama o seguinte: "Todos são iguais perante a lei, sem distinção de qualquer natureza”. Esta igualdade é chamada de igualdade formal. De acordo com ela, resta proibido que os legisladores criem ou editem leis que a violem. O princípio da igualdade garante o tratamento igualitário de acordo com a lei para todos os cidadãos.

A igualdade, de acordo com a Constituição Federal, possui, portanto, duas vertentes: A igualdade material: mandamento para que todos os seres humanos recebem um tratamento igual ou desigual, de acordo com a situação concreta. Quando as situações forem iguais, indicaria um tratamento igual, mas quando as situações forem diferentes, que haja um tratamento diferente. Já na Igualdade Formal vê-se sua presença na Constituição Federal de 1988 e que trata da igualdade perante a lei. De acordo com o artigo $5^{\circ}$, homens, mulheres e todos os cidadãos brasileiros são iguais conforme a lei. Sendo assim, diante da lei no 8213/91, que apresenta o critério objetivo da idade de 60 anos para os homens e 55 anos para as mulheres serem beneficiados com aposentadoria por idade rural deveria ter sido avaliada de uma forma mais isonômica. Estaria o legislador em desobediência à igualdade material, já que se observou que existem inúmeras diferenças regionais entre os segurados especiais nas diversas regiões do Brasil? 
O segundo princípio presente na lei que rege a aposentadoria por idade rural dos brasileiros seria o princípio da universalidade de cobertura. Este restou explicado por Juliana Ribeiro (2011, p. 65) que divide o conceito deste princípio em três partes, quais sejam:

Universalidade = igualdade isonômica (igualdade material e não formal), ou seja,
igualar os desiguais e diferenciar os desiguais. Refere-se tanto aos sujeitos protegidos
quanto ao elenco de prestações que serão fornecidas pelo sistema de seguridade social.
Cobertura = a previdência será responsável por dar cobertura às situações amparadas,
por lei, que gerem necessidade social. Assim, a cobertura refere-se a situações de vida
que serão protegidas de uma forma isonômica. Atendimento = o atendimento significa
o fornecimento de serviços e benefícios a todos os segurados, titulares do direito à
proteção social.

Sendo assim, diante desse princípio tem-se uma proteção isonômica material e não formal. Diante de tantos obstáculos que são vivenciados pelos agricultores, será que o legislador evidenciou através desse princípio as possíveis diferenças de cada região quando foi eleger a idade de 60 anos e 55 anos para homens e mulheres respectivamente?

Diante disso, outro princípio relevante para o estudo seria o da uniformidade e equivalência dos benefícios e serviços às populações urbanas e rurais. Para Edmilson de Almeida Barros Júnior (2012, p. 103), o princípio da uniformidade e equivalência dos benefícios e serviços às populações urbanas e rurais:

[...] são os pagamentos feitos aos segurados e aos seus dependentes. Serviços são bens imateriais, postos à disposição dos segurados ou dependentes. São exemplos: o serviço social e a reabilitação profissional. A uniformidade diz respeito aos aspectos objetivos, ou seja, descreve os eventos fáticos que deverão ser cobertos. A equivalência, por sua vez, vai tomar por base o aspecto pecuniário ou o atendimento dos serviços, que não serão necessariamente iguais, mas equivalentes, na medida do possível, dependendo de algumas variáveis legais (tempo de serviço, coeficiente de cálculo etc.).

Os estudos revelam que, no mínimo, esse princípio não foi observado pelo legislador no momento de aferir a idade do trabalhador rural para sua aposentadoria. Sabe-se que enquanto o trabalhador urbano inicia seu labor com uma idade mais avançada, o trabalhador rural começa sua labuta em média aos 08 anos, vivendo da roça por um tempo médio de 45 anos, não tendo direito a uma aposentadoria por tempo de trabalho digno.

Por derradeiro, serão analisados o princípio da manutenção das desigualdades e o princípio da equivalência urbano-rural. O primeiro talvez seja o mais relevante de todos, e o que possui uma menor carga valorativa. Ele se apresenta como um subproduto do postulado fundamental da igualdade (MARTINEZ, 2001, p. 184). O autor fala que a Previdência não tem a responsabilidade de alterar as desigualdades sociais existentes. Uma prova dessa afirmação resta comprovada diante de quem tem salários menores contribui menos e recebe benefícios de menor valor, não tendo relação direta com a necessidade dos indivíduos e sim com sua capacidade. Nesse diapasão, não se precisa provar que o legislador não utilizou a valoração 
correta desse princípio, uma vez que não será discutido o valor do benefício, mas critérios menos desiguais ao serem confrontados com as circunstâncias desfavoráveis ao trabalhador rural nas diversas regiões do país.

Esse é um postulado circunstancial, referido ao desenvolvimento econômico do país: não é ínsito à previdência Social em si. As desigualdades permanecerão, sendo mensuradas, então em função das necessidades (são desiguais) (MARTINEZ, 2001, p. 186).

Já o princípio da equivalência urbano-rural traz distinções entre o trabalhador urbano e o rural do ponto de vista laboral, infortunística e previdenciário. E diante desse princípio apresenta-se uma crítica em abstrato no legislador de 1991 quando realizou a interpretação dos trabalhadores urbanos e rurais sem pautar seu entendimento às condições socioeconômicas, histórico da área rural quando exigiu carência para a aposentadoria por tempo de contribuição.

Diante disso, revela-se a Teoria dos Direitos Fundamentais de Robert Alexy, que irá fazer uma crítica quando verificar-se e analisar-se como deveria ter sido fixado o critério idade para o agricultor no Brasil segundo suas regiões, bem como a ponderação dos princípios constitucionais e previdenciários que regem a aposentadoria por idade dos segurados especiais no Brasil.

\section{DA ANÁlISE DA PONDERAÇÃo DOS PRINCÍPIOS QUE REGEM A APOSENTADORIA POR IDADE DOS AGRICULTORES DO BRASIL}

A Constituição Federal de 1988 trouxe em seu art. $3^{\circ}$ os objetivos fundamentais da República Federativa do Brasil. Dentre eles encontra-se a erradicação da pobreza, a marginalização e a redução das desigualdades sociais e regionais como princípio fundamental.

Quando se fala em redução das desigualdades sociais e regionais, já foi relatado que não é da responsabilidade da previdência tal problemática, entretanto, a contrário senso, se a Constituição brasileira trouxe como um princípio fundamental a redução das desigualdades regionais, é por que elas existem e devem ser consideradas. Considerar é uma coisa. Resolver a problemática é outra totalmente diferente. Partindo então dessa premissa, pode-se trazer o foco para a realização da ponderação dos princípios envolvidos em abstrato diante da lei que instituiu a idade de 60 ou 55 anos para homens e mulheres terem direito à uma aposentadoria por idade rural.

No presente estudo, adotar-se-á a tese de que a ponderação propriamente dita, como técnica de decisão, identifica-se com a aplicação do princípio da proporcionalidade em sentido estrito que se determina que se coloque as vantagens que defluem da tutela total ou parcial de cada um dos bens jurídicos em conflito (PEREIRA, 2006, p. 266). 
No princípio da isonomia, observa-se a igualdade em sentido material e formal, que com força quer amparar os trabalhadores rurais tratando os iguais de maneira igual e os desiguais de maneira desigual. Portanto, um agricultor do nordeste que apresenta critérios diferentes dos agricultores do Sul, deve ter um tratamento diferenciado no momento da sua aposentadoria por idade. Os critérios devem ser iguais para os iguais e diferentes para os desiguais. Parte-se do critério escolaridade. Um agricultor analfabeto, que mora em uma localidade onde a sua expectativa de vida é menor que 65 anos, vivendo constantemente exposto a um clima semiárido, exposto ao sol, apresentando doenças degenerativas e que iniciou seu labor aos 12 anos de idade merece usufruir de uma aposentadoria por idade rural somente a partir dos 60 anos? Não parece razoável. Se um agricultor que mora no sudeste, com o ensino fundamental completo, não exposto ao sol do Nordeste, que iniciou sua vida laboral aos 20 anos e que tem uma expectativa de vida em torno de 75 anos, mereceria também ser aposentado por idade com os mesmos 60 anos do agricultor do Nordeste?

Já o princípio da universalidade, dispõe-se a proteger as coberturas das situações amparadas pela seguridade social. Neste caso, o princípio ampara a questão da idade avançada, proporcionando aos segurados uma proposta de igualar os desiguais e diferenciar os desiguais, entretanto, não possui uma carga valorativa significante já que não consegue refletir os critérios expostos do agricultor em cada região.

No tocante ao princípio da uniformidade e equivalência dos benefícios e serviços às populações urbanas e rurais, faz referência às necessidades dos segurados quando se encontram em uma idade avançada. O bem jurídico amparado foi a velhice, que de acordo com suas necessidades, os segurados vão ser resguardados através da prestação dos benefícios. Quer no setor rural ou urbano.

No princípio das desigualdades sociais, vemos uma carga valorativa negativa na proporção em que demonstra que a previdência não serve para equilibrar as desigualdades existentes na sociedade. Ele apenas ampara proporcionalmente os segurados na medida de suas contribuições. No caso específico dos segurados especiais, não há contribuição expressiva e, talvez por esse contingente, não haja tanta preocupação no retorno proporcional ao seu labor, criando-se métodos para a concessão dos benefícios com parâmetros etários mais isonômicos.

O princípio da equivalência urbano-rural trouxe uma carga valorativa quase que inexistente, uma vez que existe praticamente uma desigualdade material no tocante à concessão do benefício por tempo de contribuição, e pelo fato dos agricultores (segurados especiais) terem a obrigação de verterem contribuições como facultativos. 
Diante dos princípios estudados é possível se observar uma injustiça extrema segundo a teoria dos direitos fundamentais de Alexy e da inconstitucionalidade da lei $n^{\circ}$ 8213/91 quando fere cruelmente os princípios fundamentais do critério etário para a concessão de aposentadoria por idade rural dos segurados especiais.

\section{HERMENEUTICA CONSTITUCIONAL, DIREITOS FUNDAMENTAIS E A PONDERAÇÃO EM ABSTRATO DOS PRINCÍPIOS QUE REGEM A LEI 8213/91}

O estudo e crítica encontram embasamento na Teoria dos Direitos Fundamentais de Robert Alexy, que se apresenta como ponto de partida, uma análise sobre a diferença entre princípios e regras que muito irá contribuir para o entendimento das avaliações feitas pelo legislador sobre o critério idade do trabalhador rural diante da lei $\mathrm{n}^{\mathrm{o}} 8213 / 91$.

Existem inúmeros critérios para diferenciar os princípios das regras, contudo o que é mais utilizado é o da generalidade. De acordo com esse critério os princípios têm um alto grau de generalidade, enquanto as regras apresentam um baixo grau. Entretanto, é importante verificar que, nos princípios, observa-se um mandamento de otimização ${ }^{3}$. Também segundo Robert Alexy (2008, p. 102), são caracterizados por poderem ser satisfeitos em graus variados e pelo fato de que a medida devida de sua satisfação não depende somente das possibilidades fáticas, mas também das possibilidades jurídicas.

Já as regras são normas que sempre são cumpridas ou não (tudo ou nada). Se existe a validade de uma regra, deve ser realizado tudo exatamente como seu mandamento. Segundo Alexy, as regras contêm, portanto, determinações no âmbito daquilo que é fática e juridicamente possível.

Sendo assim, vê-se claramente que, quando a lei $\mathrm{n}^{\circ}$ 8213/91 rege que o homem agricultor só poderá se aposentar por idade com 60 anos e a mulher com 55, esta é uma regra que deve ser cumprida em abstrato exatamente pela sua determinação, enquanto deve-se sopesar os princípios que regem esta lei e realizar uma apreciação sobre possíveis colisões entre esses princípios.

No tocante às colisões de princípios vê-se que estas devem ser solucionadas e um dos princípios deverá ceder sem declaração de invalidez do outro, na verdade, demonstrar-se-á que, nesses casos de colisão, um dos princípios apresenta uma precedência em relação aos outros

\footnotetext{
3 O conceito de mandamento é aqui utilizado em um sentido amplo, que inclui também as permissões e proibições (ALEXY, 2008, p. 90).
}

Rev. de Direitos Fundamentais nas Relações do Trabalho, Sociais e Empresariais | e-ISSN: 2525-9903 | Maranhão | v. 3 | n. 2 | 
dentro de algumas condições. O que ocorre, na realidade, diante de uma colisão de princípios é uma avaliação na dimensão de peso e não de validade, como ocorre com a colisão das regras.

O presente estudo torna-se mais evidente e relevante no tocante ao estudo do Direito Fundamental de uma aposentadoria digna por idade ao trabalhador rural, quando este atinge os 60 ou 55 anos, mas na verdade diante da lei vigente não consegue gozar de sua proteção previdenciária por muito tempo, mais especificamente no nordeste. Importante ressaltar que mesmo frente a todas as incoerências apresentadas tais como, idade de início do labor rural, analfabetismo, ausência de aposentadoria rural por tempo de labor, sem a necessidade de recolhimento como facultativo, doenças degenerativas, o poder executivo, mesmo diante da incorreta avaliação do legislador de 1991 sobre o critério idade para a aposentadoria por idade rural, ainda procura de todas as formas aprovar uma PEC, a 287, que busca majorar para 57 anos a aposentadoria por idade rural para as mulheres, tornando assim esse critério menos isonômico do que na realidade está no momento.

Em sentido oposto, traz-se uma avaliação valorativa do princípio da isonomia em sentido formal e material versus princípio da universalidade versus uniformidade e a equivalência dos benefícios e serviços às populações urbanas e rurais versus o princípio das desigualdades sociais versus princípio da equivalência urbano rural. O objetivo desse sopesamento seria definir qual dos princípios que, de forma abstrata, estariam no mesmo nível ou os que têm maior peso com relação a lei no 8213/91.

Tencionando de um lado está o princípio da isonomia, que através das diversas situações apresentadas, como desnível de escolaridade, diferenças clima, início de vida laboral, doenças degenerativas e mortalidade, direcionam no sentido de que não seria isonômico conceder a idade da aposentadoria rural pautado em um critério único em todas as regiões do Brasil. Um homem de 60 anos que mora no sudoeste apresenta um nível de escolaridade maior, o clima favorece seu trabalho, apresenta menos doenças degenerativas e sua expectativa de vida é maior, o que leva esse agricultor a desfrutar de sua aposentadoria por muito mais tempo que o nordestino, por exemplo. Na mesma direção encontra-se um número significante de analfabetos na Região Nordeste, sacrificados pela seca, com doenças degenerativas na coluna e com uma expectativa de vida baixíssima. Essa aposentadoria por idade, sendo unificada, trouxe uma desobediência ou uma hipovaloração do princípio da igualdade. Os agricultores nordestinos vivem menos e em péssimas condições climáticas. Seria justo que essa aposentadoria só lhe fosse devida após os 60 ou 55 anos para homens e mulheres respectivamente? 
Por outro lado, tem-se o princípio da universalidade, também tencionando em sentido oposto ao do princípio da isonomia, já que essa universalidade está amparada em igualar os desiguais e diferenciar os desiguais. A lei quis igualar os agricultores de todas as regiões, sem fazer a diferenciação dos critérios que estariam envolvidos. Essa igualdade na realidade é inexistente. Observa-se, portanto, a presença do princípio da uniformidade e equivalência dos benefícios e serviços às populações urbanas e rurais no que diz respeito aos aspectos objetivos, ou seja, descreve os eventos fáticos que deverão ser cobertos. No caso, o evento a ser coberto seria a aposentadoria por idade rural com o pagamento dos valores a partir da comprovação de 15 anos de labor rural e 60 ou 55 anos para homens e mulheres respectivamente. Por derradeiro, o princípio das desigualdades sociais, que indica que a previdência não foi criada para realizar mudanças nas desigualdades sociais, mas sim para servir como fonte de sobrevivência proporcionalmente ao que foi contribuído, traz certa carga valorativa uma vez que se trata de um princípio de custeio. Existe ainda o princípio da equivalência urbano-rural, que se percebe com mínima carga valorativa uma vez que existem valores não satisfeitos entre os trabalhadores urbanos e rurais.

Eis a importância da relação de precedência condicionada, que dará uma explicação sobre a colisão dos princípios envolvidos na lei previdenciária. Neste caso, os princípios colidentes serão chamados de P1 (direito a igualdade material e formal) princípio da isonomia, P2 (direito a igualdade material exclusivamente) como o princípio da universalização e, finalmente, $\mathrm{P} 3$ (uniformidade e equivalência dos benefícios e serviços às populações urbanas e rurais), P4 (princípio das desigualdades sociais) e P5 (princípio da equivalência urbano rural).

Esses princípios serão ponderados, e serão evidenciados os equívocos do legislador ao conceder uma idade absoluta para os trabalhadores rurais das diversas regiões do país.

Segundo Robert Alexy, essa colisão de princípios pode ser resolvida ou por meio de estabelecimento de uma relação de precedência incondicionada ou por meio do estabelecimento de uma relação de precedência condicionada. Será utilizado como símbolo de precedência o sinal P. Já para as condições sob as quais um princípio tem precedência em face do outro será utilizado o sinal C. Diante dessa explanação uma colisão de princípios no caso previdenciária: P1, P2, P3, P4, P5; P2, P3, P4, P5, P, P1; (P1, P, P2, P3, P4, P5) C ou, ainda, (P2, P3, P4, P5, $\mathrm{P}, \mathrm{P} 1) \mathrm{C}$.

No caso em cena, o princípio P1 tem um peso maior que os princípios colidentes $\mathrm{P} 2$, P3, P4 e P5, já que evidenciamos razões suficientes para que P1 venha a prevalecer sobre P2, P3, P4 e P5, sob as condições C. 
Sendo assim, pode-se ver claramente que o aspecto constitucional que rege a lei $\mathrm{n}^{\circ}$ 8213/91, é gravemente violado, pois o Legislativo quando pensou na lei dos benefícios levou em conta dados estatísticos, análises gerais e generalização de situações fáticas hipotéticas e meramente imaginadas para formular enunciados igualmente gerais e abstratos. O legislador não imaginou que o agricultor do nordeste vive diante de contingências totalmente diferenciadas do agricultor do sudeste. E sendo assim, somente através de uma correta atuação do Judiciário que labora em função de dados reais, concretos, específicos e determinados poderia solucionar litígios que se lhes põem. Enquanto um realiza uma atuação abstrata, o outro possui atuação preponderantemente concreta. No sentido dos direitos fundamentais, a conclusão não seria diferente. O legislativo em sua atuação em abstrato sendo balizada pela constituição o Judiciário não poderá deixar de atuar na efetivação da Constituição, máxime diante da omissão legislativa. Em se tratando de direitos fundamentais, sua dimensão objetiva condicionará a interpretação de todos os enunciados pertinentes (pelo fenômeno que se popularizou chamar de filtragem constitucional); exigirá que o magistrado ou tribunal verifique as consequências de sua decisão para a ordem constitucional e exigirá que se adote uma postura de defesa do direito fundamental que não poderá ser tido como letra morta e plenamente carente de eficácia.

No caso em cena, quando um agricultor que sempre laborou no nordeste, analfabeto, que teve inicio seu labor rural muito cedo, deveria o judiciário realizar essa ponderação no caso concreto flexibilizando o aspecto etário no momento do pedido da aposentadoria por idade desse agricultor.

Sabe-se que nem sempre o legislador pode antever os acontecimentos que ocorrem e as contingências nos casos concretos, apenas procurou constitucionalmente traçar diretrizes objetivas no tocante aos critérios objetivos na hora de legislar sobre os critérios para a concessão de uma aposentadoria por idade aos agricultores do país.

Segundo Juraci Mourão Lopes Filho (LOPES FILHO, 2010, p. 4481) há duas maneiras de se fazer a análise prática quando da ponderação:

a) considerando casos hipotéticos, situações padrões de aplicação em que comumente estão envolvidos os direitos fundamentais a serem ponderados; b) considerando fatos reais, concretos e específicos, em função de uma situação presente e efetiva de aplicação de direitos fundamentais. A ponderação realizada no primeiro constructo será em abstrato, no segundo, em concreto.

A resposta à problemática, a priori, já foi traçada pelo Supremo Tribunal Federal, quando também diante de uma inconstitucionalidade por incompatibilidade entre a ponderação em abstrato e a ponderação em concreto, firmou entendimento sobre a aplicação do art. $20, \S 3^{\circ}$, 
da lei n. 8.742/93 que define, para fins de recebimento de benefício assistencial previsto no art. 203, V, da CF/88, o que seja idoso que não possui "meios de prover à própria manutenção ou tê-la provida por sua família”. A lei trazia como critério a renda familiar per capita inferior a um quarto de salário mínimo. No entanto, em se constatando em um caso concreto, por características que lhe são próprias e específicas, que se está diante de um miserável, apurável por critérios distintos daqueles que levaram o legislador a encontrar o proposto equilíbrio entre os direitos envolvidos, então deve a ponderação em abstrato ser afastada (por inconstitucionalidade, até porque não haveria outro meio para tanto) em prol de uma ponderação em concreto. Reparemos que, nesse caso, o julgamento normalmente não propõe uma solução padrão que pode facilmente se repetir, ou seja, não indica uma situação comum excluída da ponderação em abstrato feita pelo legislador, mas apresenta julgado próprio e adequado àquele caso, por suas peculiaridades, as quais dificilmente se repetirão em outros julgamentos ou poderia ser antevisto pelo Legislador.

Diante desse exemplo, vê-se que sua flexibilização quanto ao aspecto miserabilidade foi reconhecida. E o que na realidade seria miserabilidade? Existe atualmente uma carta em branco fornecida pelo STF ao Magistrado a quo para que realize essa ponderação em concreto. Portanto, analogamente torna-se viável esta mesma aplicação nos casos de aposentadorias por idade rural, quando os agricultores estiverem buscando uma aposentadoria por idade rural. A idade na realidade seria somente um norte. O que na realidade proporcionaria a resolução da problemática seria a aferição da idade em harmonia com as contingências de cada região e suas peculiaridades já tão amplamente discutidas anteriormente.

\section{CONCLUSÃO}

À guisa de conclusão, pode-se afirmar que a lei 8213/91 carece de constitucionalidade no tocante a regra etária para a concessão da aposentadoria do trabalhador rural brasileiro.

Diante dos princípios que regem a lei 8213/91, viu-se que, apesar da carga valorativa de cada um, fazendo um sopesamento segundo a Teoria dos Direitos Fundamentais de Robert Alexy, o legislador não considerou os critérios de acordo com as contingências das diversas regiões brasileiras com intuito de proporcionar um tratamento isonômico. O analfabetismo, o clima, a idade do início do labor, as doenças degenerativas, a exposição ao sol e expectativa de vida deveriam ter sido consideradas para que essa idade fosse flexibilizada a depender da região. 
Viu-se ainda que restou comprovado, através do sopesamento dos princípios, que regem o direito previdenciário e a constituição, que a lei 8213/91 não deveria trazer uma equação protetiva da velhice do agricultor somente através da fixação de uma idade unificada, já que em algumas regiões o agricultor nem sequer chega a gozar de sua aposentadoria. Os princípios constitucionais e previdenciários envolvidos possuem pesos diferentes, segundo a teoria de Robert Alexy, o princípio da isonomia torna-se forte o suficiente para que a tese decorrente do seu peso seja confirmada no caso pela inconstitucionalidade do critério etário para a concessão de aposentadoria por idade rural com critérios diferentes de acordo com as contingências das diversas regiões brasileiras.

Entretanto, verificando mais de perto o princípio da equivalência urbano-rural, observou-se o descaso do legislador ao reconhecer a existência da aposentadoria por tempo de contribuição do trabalhador urbano e afastando esta mesma aposentadoria para o segurado especial, que carece de contribuições, mas que, ao mesmo tempo, é considerada se forem efetivadas as contribuições como facultativo. Infelizmente os agricultores do país, pelo menos do nordeste, não têm condições para verter tais contribuições. A distância encontrada nos direitos desses trabalhadores não deveria existir uma vez que o agricultor inicia sua vida laboral bem mais cedo que qualquer trabalhador urbano, merecendo, portanto, uma aposentadoria por tempo de labor rural, para que restasse uma constitucionalização do critério idade nas diversas regiões brasileiras. Essa seria a única opção para que a lei 8213/91 contemplasse uma aposentadoria digna para todos os agricultores do país. Oportunizar aos segurados especiais uma aposentadoria pautada no tempo de labor rural em regime de economia familiar.

\section{REFERÊNCIAS}

ALEXY, Robert. Teoria dos Direitos Fundamentais. $5^{\circ}$ ed. Trad.: Virgílio Afonso da Silva. São Paulo: Malheiros, 2008.

BARROS, Edimilson De Almeida. Direito Previdenciário Médico. São Paulo: Editora Atlas, 2012.

BERWANGER, Jane W. Previdência Rural: Inclusão Social. Curitiba: Juruá, 2007.

BRASIL. Constituição (1988). Lex: legislação federal e marginália, São Paulo, v. 59, p. 1966, out./dez. 1995.

BRASIL. Lei $\mathrm{n}^{\mathrm{o}}$ 8.213, de 24 de Julho de 1991. Disponível em: <http://www.planalto.gov.br/ccivil_03/leis/L8213cons.htm>. Acesso em: 12 jun. 2017.

Rev. de Direitos Fundamentais nas Relações do Trabalho, Sociais e Empresariais | e-ISSN: 2525-9903 | Maranhão | v. 3 | n. 2 | 
BRASIL. Superior Tribunal de Justiça. Súmula $\mathrm{n}^{\circ}$ 272. Disponível em: <http://www.conteudojuridico.com.br/sumula-organizada,stj-sumula-272,2655.html>. Acesso em: 20 jun. 2017.

CRUZ, Elaine; BRANCO, Mariana. Reforma da Previdência terá de lidar com disparidade de expectativa de vida. Agência Brasil, 15 nov 2016. Disponível em: $<$ http://agenciabrasil.ebc.com.br/politica/noticia/2016-11/reforma-da-previdencia-tera-delidar-com-disparidade-de-expectativa-de-vida>. Acesso em: 25 jun. 2017.

GALIZA, M.; VALADARES, A. Previdência Rural: Contextualizando o Debate em Torno do Financiamento e Das Regras de Acesso. Nota Técnica nº 25 IPEA. Brasília: IPEA, 2016.

GONÇALVES, José Wilson (coord.). Previdência Social Rural: Potencialidades e Desafios. Brasília: $\quad$ CONTAG, 2016.20 Disponível <http://www.contag.org.br/arquivos/relatorio_previdencia\%202.pdf>. Acesso em: 20 jun. 2017.

INCA. 27 de novembro - Dia Nacional de Combate ao Câncer. 2017. Disponível em: <http://www.inca.gov.br/wcm/dncc/2015/por-regioes.asp>. Acesso em: 12 ao. 2017.

LEAL, Aline. População rural do Brasil é maior que a apurada pelo IBGE, diz pesquisa. Agência Brasil, 92015.2 Disponível em: <http://agenciabrasil.ebc.com.br/geral/noticia/2015-03/pesquisa-diz-que-populacao-rural-dobrasil-e-maior-que-apurada-pelo-ibge> . Acesso em: 13 jun. 2017.

LOPES FILHO, Juraci Mourão. O Limite à Atuação Jurisdicional Dos Direitos Fundamentais Com Reserva Legal. In: Congresso Nacional do CONPEDI (19: 2010: Fortaleza, CE) Anais do XIX Congresso Nacional do CONPEDI, p. 4476-4487. Fortaleza, 2008.

MAIA, Alexandre G.; BUAINAIN, Antonio M. O Novo Mapa da População Rural Brasileira. Confins - Revue franco-brésilienne de géographie. 19 Novembro 2015. Disponível em: <http://confins.revues.org/10548>. Acesso em: 17 jun. 2017.

MARTINEZ, Wladmir. Princípios do Direito Previdenciário. $4^{\text {a }}$ Ed. São Paulo: LTR, 2001.

MENEGAT, Robiane P. Condições de Trabalho do Trabalhador Rural e sua Interface com o Risco de Adoecimento. Revista Ciência, Cuidado e Saúde v. 9, n. 1, 2010. Disponível em: < http://periodicos.uem.br/ojs/index.php/CiencCuidSaude/article/view/7810>. Acesso em: 26 jun. 2017.

MOREIRA, Jessica Pronestino de Lima; et al. A saúde dos trabalhadores da atividade rural no Brasil. Cad. Saúde Pública [online]. 2015, vol.31, n.8, pp.1698-1708.

PEREIRA, Jane Reis G. Interpretação constitucional e direitos fundamentais: uma contribuição ao estudo das restrições aos direitos fundamentais na perspectiva da teoria dos princípios. Rio de janeiro: Renovar, 2006.

RIBEIRO, Juliana de Oliveira Xavier. Direito Previdenciário Esquematizado. São Paulo: Quartier Latin, 2011. 